AKRUAL 3 (1) (2011): 38-57 e-ISSN: 2502-6380

AKRUAL

Jurnal Akuntansi

http://fe.unesa.ac.id/ojs/index.php/akrl

\title{
SIKAP SOSIO-SPRITUAL DALAM AKUNTANSI KONTEMPORER: TELAAH, TANTANGAN DAN IMAJINASI DIRI
}

\author{
Diah Hari Suryaningrum \\ Universitas Pembangunan Nasional "Veteran" Jawa Timur \\ Email: diahrkt@yahoo.com
}

Artikel diterima: 20 Agustus 2011

Terakhir direvisi: 27 Oktober 2011

\begin{abstract}
This paper is attempted to explore, challenge, and imagine contemporary accounting and its role in socio-spiritual manner. In exploring contemporary accounting such as social accounting and spiritual accounting, I found that their emerging in new accounting is really needed. Even if social accounting have been found centuries ago, their development is increased when people aware not only that their action is affected in economy wealth, it is also influenced their social, environmental, and sustainability development. Accounting is trying to measure this externalities cost. Some are skepticism with the effort since in reducing these externalities of environmental destructions; it will not support the notion of social contract. Likewise, spiritual accounting is also trying to concern for others but in a spiritual point of view. This new development in accounting is a challenge for accounting profession in a way how they have to behave. Accountants not only have to obey to accounting profession code of ethics, they also have to practice accounting in their sociospiritual manner. This paper is concluded with the notion that whatever role accounting choose, it is up to the accountant to take part in that role.
\end{abstract}

Keywords: Contemporary accounting, social accounting, spiritual accounting, sociospiritual manner, altruistic.

\section{PENDAHULUAN}

Akuntansi bukan sekedar debet kredit, catatan, hitungan, dan lainnya yang ujung-ujungnya adalah uang. Di Indonesia, pandangan masyarakat umum tentang akuntansi masih belum berubah dari hitungan dan uang. Ada suatu kejadian yang saya alami yang terjadi pada saat saya menunggu giliran pelayanan di sebuah bank. Di samping saya duduk seorang ibu, dan entah bagaiman kita kemudian membicarakan tentang anak ibu itu yang berhasil diterima di Fakultas Ekonomi jurusan Manajemen. Saat itu saya tanyakan "kok tidak ambil jurusan akuntansi?" Jawabnya "gimana ya jeng, anak saya itu tidak pandai hitung-hitungan". Hal ini menunjukkan pandangan yang sempit tentang akuntansi. Bahkan ada yang berpendapat akuntansi adalah loket tempat pembelian tiket film di bioskop. 
Dalam lingkungan akademik atau pendidikan tinggi yang menghasilkan sarjana akuntansi, pandangan tentang akuntansi juga masih memprihatinkan. Pendidikan akuntansi cenderung untuk melihat dan "memotret" akuntansi sebagai proses yang merepresentasikan realitas keuangan dan ekonomi, umumnya dengan dasar angka atau bentuk standar moneter lainnya. Pandangan ini membatasi akuntansi hanya pada identifikasi, pencatatan, pengukuran dan pengkomunikasian informasi ekonomi (Blair et al., 2007). Sebagai akibatnya, para mahasiswa atau sarjana akuntansi masih berpendapat akuntansi hanya bisa berperan untuk penyusunan laporan keuangan, pemeriksaan laporan keuangan, perekayaasaan laporan pajak, system informasi akuntansi, dan peran-peran "tradisional" lainnya.

Pada kenyataannya akuntansi sudah mulai berkembang dengan pesat sejak dipopulerkannya tata buku berpasangan oleh Luca Pacioli (1941). Akuntansi bukan lagi dimaknai sebagai angka-angka. Pentingnya pemaknaan yang non-ekonomi, nonkeuangan, dan non-kuantifikasi diperlukan untuk melihat akuntansi sebagai "beyond numbers". Chua (1996:154) mengekspresikan pemaknaan angka yang tidak sempit sebagai berikut:

Numbers do not intrinsically enslave, they do so when numbers which appear "neutral" to one set of debates are taken to be neutral absolutely, their persuasive power is decontextualised (both culturally and historically), their limitations as modes of representing social life are downplayed and their dominance rules out all debates about the political ideas and values in which quantification itself expresses.

Pemaknaan angka yang di-dekontekstualisasi melalui budaya dan histori tersebut, membuat peranan akuntansi bukan lagi sekedar peranan "tradisional" yang selama ini dipahami, akan tetapi berkembang ke dalam konteks sosial, budaya, histori, dan spiritual. Konsep tentang pertangungjawaban dalam akuntansi juga mulai berubah. Meskipun tidak bermaksud untuk mengurangi pertanggungjawaban keuangan, meluasnya konsep pertanggung jawaban yang "non-keuangan" menjadi suatu tantangan bagi akuntan.

Dari aspek riset akuntansi, riset akuntansi sudah lebih melebar dengan menarik perspektif yang berbeda dari cabang-cabang ilmu yang lain seperti psikologi, sosiologi, budaya, agama, histori, dan spiritual (Gray, 1988; Brown, et al., 1990; Chua, 1996; Venkatesh, 2010). Meluasnya paradigm akuntansi tersebut tidak lain disebabkan oleh riset yang selama ini didominasi oleh paradigm positivism dianggap memiliki kekurangan dalam mengembangkan akuntansi. Paradigm seperti paradigm interpretif, kritis, dan posmodernis mulai lebih diperhatikan disamping paradigm positivism. Meluasnya riset akuntansi tersebut membuktikan makin luasnya peran akuntansi dalam masyarakat. Sebagai akibatnya, muncullah akuntansi kontemporer seperti social accounting, environmental accounting, sustainability accounting, dan spiritual accounting.

Tulisan ini dibagi dalam tiga bagian utama. Bagian pertama akan membahas akuntansi kontemporer, dilanjutkan ke bagian kedua tentang peran dan tantangan akuntan kontemporer yang memiliki sikap sosio-spiritual dengan adanya 
perkembangan akuntansi. dan pada bagian ketiga, saya mencoba menuangkan gagasan tentang akuntansi di masa depan melalui suatu imajinasi diri. Bagian ketiga ini saya tulis karena terinspirasi dari tulisan Sunder (2007) yang mengatakan:

".........modern miracles of airplanes, computers, space exploration, and sewage systems, indeed all science and engineering, are result of our imagination. None would have been possible had someone not dared to imagine them into existence".

\section{Akuntansi Kontemporer}

Kata akuntansi kontemporer adalah terjemahan dari contemporary accounting. Kata contemporary, dengan menggunakan google translater dan pada kamus bahasa Inggris digital memiliki banyak arti, yaitu semasa, sejaman, masa kini, modern, jaman sekarang, atau kontemporer. Dalam bukunya yang berjudul “Accounting Theory: Contemporary Accounting Issues", Evans (2003), pada bagian kedua dari isi buku tersebut, membahas isu-isu kontemporer dari pelaporan keuangan yang dihubungkan dengan perkembangan rerangka konseptual oleh FASB. Beberapa area kontroversial, seperti arus kas, akuntansi pensiun, post employment benefit dan opsi saham dibahas dalam konsteks FASB tentang definisi asset dan liabilitas.

Akuntansi kontemporer yang dibahas oleh Evans (2003) masih berorientasi pada paradigm positivism. Tulisan ini tidak mungkin tidak membahas akuntansi kontemporer dalam konteks FASB atau standard setter lainnya, karena FASB dan standar setter adalah bagian dari interaksi sosial dan orgnisasional. Meskipun demikian, tulisan ini lebih ditekankan pada akutansi yang berhubungan dengan aspek manusia itu sendiri, yaitu aspek sosial dan spriritual. Oleh karena itu, pada bagian ini akan dibahas akuntansi yang lain, yaitu social accounting, yang termasuk didalamnya dibahas environmental accounting dan sustainability accounting, dan paling akhir akan dibahas tentang spiritual accounting.

\section{Sosial Accounting}

Apa itu akuntansi sosial? Cukup sulit untuk menjawab pertanyaan tersebut. Kalau kita membaca berbagai literature dan jurnal akuntansi, kita akan melihat bahwa akuntansi sosial memiliki variasi dan bentuk yang sangat luas. Istilah akuntansi sosial tampaknya digunakan untuk menggambarkan semua hal tentang akuntansi yang berada "diluar ekonomi" atau "beyond economy". Istilah yang kita jumpai yang juga sering disederhanakan menjadi akuntansi sosial, diantaranya adalah: social responsibility accounting, corporate social reporting, employee and employment reporting, stakeholder reporting, environmental reporting, dan yang paling baru adalah sustainability accounting and reporting.

Apabila kita perhatikan sejarahnya, akuntansi sebagai produk interaksi sosial sebenarnya sudah ada sejak dulu. Pentingnya akuntansi dalam kehidupan sosial oleh Marx diakui sebagai alat yang penting untuk pengambilan keputusan rasional oleh kaum kapitalis. Marx menganggap akuntansi sebagai fenomena ideology. Berikut kutipan Burchell et al. (1980), tentang pendapat Marx bahwa: 
"Marx claim to reveal the social rationality of accounting which consist of its mystifications of the true nature of social relationship.... the subjective productive forces of labour appear as productive forces of capital."

Dalam konteks pemikiran Marx tersebut, akuntansi dipandang sebagai alat untuk mengoperasionalisasikan perbedaan ekonomi dan sosial yang dominan. Terbentuknya batasan-batasan simbolik menjadi dasar munculnya rasionalisasi. Hal inilah yang dianggap sebagai sumbangan akuntansi terhadap terbetuknya masyarakat seperti yang kita ketahui sekarang ini.

Dalam perkembangan akuntansi kontemporer saat ini, akuntansi tidak lagi dipandang sebagai fenomena teknis murni, akan tetapi mulai dipandang sebagai fenomena sosial. Akuntan yang selama ini tidak mau terlibat pada kegiatan lain selain kegiatan ekonomi, akhirnya, pada akhir tahun 1960 dan awal tahun 1970, beberapa akuntan mulai tertarik untuk berpartisipasi dalam membangun akuntansi sosial. Pengakuan dan ketertarikan terhadap akuntansi sosial berkembang secara kontemporer terjadi karena kekhawatiran terhadap etika perusahaan, kekuasaan perusahaan, dan menurunnya ekologi lingkungan. Usaha-usaha dilakukan untuk mengeksplorasi pertanggung jawaban manajerial dan sosial perusahaan, yang kemudian memunculkan istilah baru social audit, social performance, dan social disclosure and accountability. Bersamaan dengan itu meningkat pula praktik-praktik audit sosial, meningkatnya perhatian terhadap metode untuk mengukur "social performance" dan pertumbuhan yang teratur dalam bentuk tulisan jurnal dan artikel. Dalam jurnal dan artikel tersebut, perhatian utama ditekankan untuk melakukan rekonseptualisasi (re-conceptualize) pengertian tentang "business and society" (Gray, 2002).

Kalau demkian, apa itu akuntansi sosial? Definisi sosial accounting, seperti yang dikutip oleh Gaffikin (2008:200) adalah:

".....social accounting is the modification and application, by accountants, of skills, techniques, and discipline of conventional (managerial and financial) accounting, to the analysis and solution of problem of social nature" (Seidler and Seidler, 1975; pp. ix)

Menurut rerangka teoritis Bunge's, sama seperti ilmu sosial lainnya, akuntansi memiliki dua tujuan yaitu, tujuan kognitif atau intrinsic dan tujuan utilitarian atau ekstrinsik. Tujuan kognitif berusaha untuk memahami objek dengan berusaha memahami "what is", yang pada intinya akan membantu kita untuk memahami realitas sosial. Sedangkan tujuan utilitarian berusaha untuk memahami "what should $b e$ ", yang akan membatu kita memngembangkan aspek teknologikal, yang nantinya akan membantu dalam meningkatkan kesejahteraan sosial dari realitas tersebut (Barrachina, et al., 2004). Sehubungan dengan fungsi akuntansi sebagai alat untuk pengambilan keputusan (decision usefulness theory) dan sebagai alat pertanggung jawaban (stewardship theory), maka dari definisi tersebut, dapat ditarik kesimpulan bahwa akuntansi sosial adalah modifikasi dari akuntansi konvensional yang bertujuan 
untuk menganalisis dan memecahkan masalah yang berhubungan dengan masalah sosial dan memberikan pertanggung jawaban kepada public.

Pertanggung jawaban sosial perusahaan (corporate social responsibility/CSR) menurut Estes (1976:19) seperti yang dikutip oleh Gaffikin $(2008 ; 202)$ terdiri dari: 1) keterlibatan dengan komunitas sosial - meliputi aktivitas-aktivitas sosial yang terutama bermanfaat bagi public yang terdiri dari badan kemanusiaan, pendidikan, kesehatan, perumahan, dan sejenisnya. 2) Sumber daya manusia - aktivitas-aktivitas internal perusahaan yang diarahkan pada kesejahteraan karyawan yang meliputi imbalan, pelatihan, dan kondisi kerja yang aman dan sehat. 3) sumber daya fisik dan kontribusi terhadap lingkungan - misalnya: kebijakan perlindungan terhadap tanggung jawab lingkungan, dan 4) kontribusi produk atau jasa - kualitas produk, pertanggung jawaban dalam memberi label merek, pelatihan pemasaran dan pelanggan. Dengan demikian, akuntansi sosial adalah akuntansi yang memberikan pelaporan atas aktivitas perusahaan yang menekankan perlunya identifikasi perilaku sosial yang relevan, yang berisi pertanggung jawaban kinerja sosial dengan menggunakan pengukuran dan teknik pelaporan yang tepat.

Social accounting sering kali diasosiasikan atau tidak dibedakan dengan dengan environmental accounting. Kekhawatiran terhadap kondisi lingkungan telah menjadi issue paling penting bagi masyarakat di seluruh dunia. Dua masalah lingkungan penting yang diangkat adalah masalah polusi udara dan manajemen kualitas air, yang terjadi karena adanya pemanasan global (global warming). Global warming menjadi perhatian masyarakat luas. Dalam lingkungan akademik, berbagai cabang ilmu memberikan perhatiannya. Tidak mengherankan bila masalah ini juga menjadi perhatian komunitas akuntansi. Sehingga, apa yang semula dikenal sebagai corporate social reporting mulai berubah menjadi social and environmental reporting atau social and environmental accounting.

Akuntansi konvensional, selama ini mengukur kinerja perusahaan hanya berdasarkan angka-angka yang menunjukkan keuntungan atau kerugian perusahaan serta dampak laporan terhadap pengambil keputusan, tanpa memperhatikan dampak eksternal lingkungan. Dengan makin meningkatnya kesadaran lingkungan sosial, para periset akuntansi mulai mencari cara untuk menentukan bagaimana biaya eksternal (biaya lingkungan) dilaporkan dalam laporan keuangan. Menurut Gaffikin (2008, 205-206), upaya untuk menilai biaya ekternal tidak mungkin dilakukan. Alasanya:

"If traditional economic analysis ignores externalities and if conventional accounting derives from traditional economic theory, then how could externalities be reported? Problems of definition, measurement, and valuation would (and did) rise. And in addition to problems of measurement there were philosophical issues. If the environment were reduced to economic measures, how would this affects the way the environment was treated by accountants? .... Reduced to this, the environment is brought down to simple cost-benefit economic analysis and there is little support for the notion of the so-called social contract!" 
Perkembangan selanjutnya dari akuntansi sosial dan lingkungan adalah apa yang mulai dikenal sebagai "sustainability accounting". Istilah sustainability accounting bermula dari istilah sustainability development yang sering kali dikutip pada tahun 1992 dalam acara "The Earth Summit" di Rio de Janeiro. Sustainability development didefinisikan sebagai "....development that meets the needs of the present world without compromising the ability of future generations to meet their own needs." (Gaffikin 2008:206; Wolcott, 2010)

Meskipun menggunakan istilah yang berbeda, sustainability accouting masih berhubungan dengan akuntansi lingkungan dan sosial. Tujuan utama dari sustainability accounting adalah kesadaran terhadap isu-isu lingkungan dan sosial dalam bisnis serta mengembangkan nilai-nilai professional. Terdapat lima tipe modal perusahaan - natural, human, social, manufactured, and financial capital - yang mencerminkan peran organisasi seutuhnya dan kekayaannya. Berdasarkan lima modal perusahaan tersebut, terdapat tiga dasar yang utama yang ingin dicapai dalam sustainabilitiy accounitng, yaitu: kinerja lingkungan, kinerja sosial, dan kinerja ekonomi (Wolcott, 2010).

\section{Spiritual Accounting}

Beberapa kejadian yang terjadi akhir-akhir ini menjadi keprihatinan kita semua. Masalah yang ada tampaknya timbul karena kurangnya manusia dalam menanamkan nilai-nilai luhur (nilai kebajikan), baik itu yang ada pada norma-norma sosial atau nilai-nilai spiritual. Perusahaan umumnya masih membawa ajaran kapitalis yang lebih mementingkan individualism tanpa memperhatikan pihak lain yang mungkin dirugikan. Keserakahan perusahaan, membuat mereka melakukan segala cara untuk memperoleh keuntungan. Di dunia, kasus-kasus seperti Enron, WorldCom, Tyco, Adelphia, diikuti oleh Bristol Myers, AIG, Xerox, dan yang lainnya, merupakan skandal yang memalukan profesi akuntan. Di Indonesia, laporan perbankan yang memiliki opini wajar, ternyata kemudian dilikuidasi. Di Kabupaten Sidoarjo, tragedi lumpur Lapindo hingga saat tulisan dibuat masih menjadi masalah, yang tampaknya, tidak ada pihak-pihak yang berminat untuk menyelesaikan masalah tersebut. Kerugian yang timbul tidak hanya berupa materi dan jiwa, akan tetapi juga berupa "heritage". Kasus Lapindo berhasil menghancurkan sebuah komunitas sosial (masyarakat). Akankah dampak dari tindakan kita saat ini menjadi warisan bagi generasi berikut?

Turner (2006) menelaah skandal yang ada karena kurangnya profesionalisme dan regulasi dari pemerintah dan standard setter. Benarkah bila ada standar dan regulasi yang lebih ketat skandal tersebut tidak akan terjadi? Apakah benar kesalahan yang timbul karena kurangnya profesionalisme? Apakah ada nilai-nilai luhur yang tidak dimasukkan dalam profesinalisme? Devamrita Swami, seorang rahib atau biarawan lulusan universitas Yale mengatakan sebagai berikut:

"Since all major decisions in society are made with the help of money, it essentially decides what society is like. Money influence what we do, what we buy, and where we work. The current accounting system is 
concerned primarily with profit maximation at any cost and the result is the worst ever economic crises, worldwide consumer culture, global poverty and more impending crises. Ancient knowledge of east explains that the root of all manmade crises, lie in polluted consciousness. For a harmonious and sustainable society we need an accounting system that looks beyond the 'green buck' and consider all the need of the self'.

Dari perkataan Swami tersebut, tampaknya ada dua aspek dalam kehidupan manusia, yaitu individualism dan harmonious and sustainable society. Manusia, untuk berkembang secara fisik, membutuhkan "sandang, pangan, dan papan" - yang membantu mereka untuk bekerja keras menghasilkan uang untuk memenuhi kebutuhannya. Pertumbuhan fisik manusia, yang sering dimanifestasikan dengan uang, merupakan roda penggerak berjalannya perekonomian. Akan tetapi, seberapapun kuatnya seorang manusia, dia memerlukan bantuan orang lain dalam hidupnya. Artinya, manusia berada pada lingkungan sosial. Pertumbuhan sosial tidak mungkin terjadi tanpa adanya pertumbuhan emosional yang makin matang dan bijaksana dari warganya. Budaya, pendidikan, seni dan bahasa merupakan manifestasi fisik, mental, dan emosional yang ikut memberikan sumbangan positif pada perkembangan sosial.

Venkatesh (2010) menyatakan bahwa bekerja tidak hanya untuk mencari kepuasan fisik atau pembangunan fisk saja, akan tetapi merupakan pembangunan manusia seutuhnya yang mencakup pembangunan fisik, mental-emosional-psikologi, dan spiritual. Atau dengan kata lain, pembangunan badan, pikiran, dan jiwa (body, mind, and soul). Dalam terminologi Islam, bekerja memiliki dua dimensi yang penting yaitu dimensi duniawi dan dimensi ibadah. Bekerja bukan semata-mata sebagai upaya untuk memenuhi kebutuhan hidup secara layak namun lebih daripada itu bekerja merupakan kegiatan ibadah yang mendatangkan pahala dan kebaikan baik di dunia maupun akhirat kelak. Hal ini sejalan dengan dengan Syafiq dan Achmad (2002) yang menyatakan bahwa bekerja merupakan perbuatan yang sarat dengan nilai-nilai religius.

Pemahaman terhadap spiritualitas manusia telah menjadi bahan pemikiran para filsuf. Pertanyaan tentang apakah manusia itu secara lahiriah baik atau buruk, telah menjadi permasalahan tidak hanya bagi para ahli agama tetapi juga bagi para ahli filsafat (filsuf) dalam bidang yang disebut sebagai filsafat moral atau "moral philosophy". Moral sering dicerminkan sebagai perilaku etis manusia (ethical human behavior). Banyak orang percaya bahwa perilaku etis dibentuk dari prinsip-prinsip moral yang diajarkan oleh agamanya - ada ajaran atau prinsip-prinsip atau "code" yang menuntun tindakan manusia di dunia - misalnya, umat Kristiani mengenal "Ten Commandmends". Akan tetapi sejarah membuktikan bahwa pada hampir semua agama, prinsip-prinsip tersebut menjadi subyek yang banyak diperdebatkan, dan bahkan menghasilkan suatu tindakan yang bertentangan dengan prinsip itu. Contohnya, salah satu dari "Ten Commendments" menyatakan bahwa "Thou shalt not kill", akan tetapi sejarah manusia membuktikan bahwa mereka berusaha merasionalisasi "pembunuhan" pada kondisi tertentu seperti saat perang. Ketidak 
konsistenan ajaran dengan perilaku etik tidak hanya ada dalam agama Kristen, akan tetapi hal yang sama juga terjadi dalam agama Hindu, Budha, Islam dan ajaran lainnya (Gaffikin, 2008:168).

Pemikir Yunani, Plato, seorang rasionalis, percaya bahwa "pure form" termasuk moralitas - ada dan hanya dapat ditemukan melalui akal sehat (reasoning). Manusia mengetahui apa yang salah dan apa yang benar, sehingga tindakan moral dilaksanakan berdasarkan kesadaran akan tanggung jawabnya. Tanggung jawab tersebut ditentukan melalui akal sehat. Sayangnya, kita mungkin tidak mempunyai kekuasaan terhadap apa yang benar dan apa yang salah. Tidak ada dasar rasional dari moralitas, moral lebih banyak dibentuk oleh keadaan, politik, dan ideology tentang "siapa yang lebih berkuasa" - yaitu mereka yang memiliki kemampuan untuk meyakinkan apa yang dimaksud dengan benar. Contohnya, seorang akuntan mungkin diarahkan untuk melakukan suatu tindakan tertentu dalam situasi tertentu karena atasannya mengatakan bahwa tindakan tersebut adalah tidakan yang terbaik bagi perusahaan danbagi klien, meskipun dia percaya bahwa tindakan tersebut tidak etis. Kurangnya moralitas, akan mengarahkan kita pada tindakan-tindakan tidak etis yang berdampak pemusnahan (contohnya yang terjadi pada kasus lumpur lapindo), penyiksaan, terorisme, rusaknya lingkungan, dan hal-hal buruk lainnya yang telah dijustifikasi dengan dasar apa yang disebut "prinsip" dan "public interst". Dalam lingkungan bisnis, hal ini dicerminkan dengan keserakahan, nepotisme, corporate corruption, yang seringkali berakibat kerugian ekonomis atau bahkan kehancuran pihak lain yang tidak berdosa. Salah satu contoh kasus di Indonesia adalah kasus gas elpiji $3 \mathrm{~kg}$. Dalam salah satu kuliah tamu pada saat orientasi pendidikan mahasiswa baru program pascasarjana Universitas Brawijaya tahun ajaran 2010/2011, diundang salah satu direktur Pertamina untuk berbicara tentang "good corporate governance". Saat mahasiswa bertanya tentang kasus elpiji tersebut dan hubungannya dengan tindakan "good corporate governance" Pertamina. Oleh direktur tersebut dijawab bahwa Pertamina hanya diberi waktu 3 bulan oleh pemerintah untuk melaksanakan program pemerintah yaitu mengganti minyak tanah dengan elpiji. Kasus ini menurut pendapat saya merupakan contoh pembenaran atau justifikasi melakukan tindakan yang sebenarnya tidak etis. Mengapa? Karena kalau memang mereka menerapkan "good corporate governance", maka produk yang dihasilkan harusnya sudah melalui uji kualitas dan tidak berbahaya bagi pengguna atau konsumen.

Francis (1990) seperti yang dikutip oleh Gaffikin (2008:184), menyarankan 5 (lima) kebajikan yang mungkin termasuk "unik" didalam praktik akuntansi, yaitu, honesty, concern for the economic status for others, sensitivity to the values of cooperation and conflict, communicative character of accounting, and dissemination of economic information. Francis juga berargumen bahwa "worship of money", akhirakhir ini telah banyak mempengaruhi praktik-praktik akuntansi. dan ia menyimpulkan bahwa "akuntansi", jika memang merupakan "kebajikan", maka akuntansi harus memproklamirkan bahwa akuntansi adalah hasil kreasi manusia dan merupakan "agen" moral itu sendiri. 
Dengan demikian, apa yang dimaksud dengan akuntansi spiritual? Swami dalam salah satu ceramahnya mendefinisikan akuntansi spiritual sebagai berikut:

"Spiritual accounting is the consideration of not just fiscal gain and loss, as mainstream accounting does, but also of all the factors of human life and its impact: physical, mental, ecological, and certainly spiritual. Spiritual accounting means: 'Let's wise up-we must see the whole balance sheet of human existence, not just the dollars and cents.' When seen in this way, our so-called economic development may actually be uneconomic, when all the ecological, health, and spiritual costs and damages are tabulated. Accounting, so much at the heart of our current attempt at civilization, can actually become real accounting by consideration of all the aspects of our life, rather than giving us merely a distorted report of just financial profit and loss."

Selanjutnya akuntansi mengalami diferensiasi yang begitu pesat setelah "perkawinannya" dengan ilmu sosiologi (akuntansi disepakati sebagai bagian dari ilmu sosial) sehingga wajah akuntansi berubah dari sebatas bersifat teknis pencatatan (benda mati) menjadi lebih bernyawa dengan sosio spiritualitas akuntansinya. Mengutip pernyataan Sukoharsono (2008) bahwa "accounting is not just a simple of numbers and tables; it is also about spirituality that is a meta-physical matter".

\section{PEMBAHASAN}

\section{Sikap Sosio-Spiritual Dalam Akuntansi Kontemporer: Suatu Tantangan}

Skandal-skandal keuangan yang melibatkan profesi akuntan publik membuat kepercayaan terhadap akuntansi dan akuntan berkurang. Perlu kita perhatikan disini bahwa skandal tersebut sebenarnya tidak hanya melibatkan akuntan publik yang mengaudit laporan keuangan serta memberikan opininya, akan tetapi juga akuntan internal (akuntan manajemen) yang membuat laporan keuangan. Perlu kita cermati lebih jauh, bahwa yang melahirkan akuntan publik dan akuntan manajemen atau profesi akuntan lainnya adalah akuntan pendidik. Pertanyaannya kemudian menjadi: Apa ada yang salah dengan akuntansi? Ataukah ada yang salah dengan profesi akuntan? Apakah sikap sosio-spiritual tidak tercermin dan dipraktikkan oleh akuntan?

Apa yang salah dengan akuntansi kontemporer modern saat ini? Triyuwono (2006) menyatakan bahwa akuntansi modern tidak mampu merefleksikan realitas non ekonomi yang diciptakan perusahaan. Ia hanya mampu mengakui dan merefleksikan peristiwa ekonomi saja. Triyuwono (2006) juga secara sistematis menjelaskan beberapa kelemahan yang muncul berkaitan dengan praktik akuntansi konvensional (modern) yakni: (1) Akuntansi modern mengabaikan dua aspek penting yaitu lingkungan dan sosial sehingga gagal menggambarkan realitas bisnis yang semakin kompleks; (2) Sifat egoisme sangat melekat pada akuntansi modern sehingga terefleksi ke dalam bentuk private costs/benefits dan berorientasi melaporkan profit untuk kepentingan pemilik modal/pemegang saham. Oleh karena itu informasi akuntansi menjadi egois dan mengabaikan pihak lain; (3) Akuntansi modern lebih bersifat materialistik sehingga memarjinalkan nilai-nilai spiritualitas padahal manusia 
sebagai pelaku akuntansi memiliki dua hal tersebut yakni material dan spiritual. Jika manusia diarahkan untuk menjalankan praktik akuntansi yang beorientasi pada materi (profit) maka perilaku yang muncul berkaitan dengan upaya pencapaian tujuan tersebut berpotensi melanggar aturan dan kehilangan nilai-nilai etika, agama dan moralitas.

Profesi akuntan, sebagaimana kita ketahui, dilandasi oleh kode etik professional. Mengapa kode etik diperlukan? Pada abad 17, Thomas Hobbes, seorang ahli filsafat, memperkenalkan "psychological egoism", yang beranggapan bahwa manusia pada hakikatnya adalah wujud yang tidak baik (nasty entity). Oleh karena sifatnya yang tidak baik tersebut, maka untuk menghindari konflik antar manusia, Hobbes memperkenalkan apa yang disebut "kontrak sosila (social contract)". Kontrak sosial ini adalah sebuah "persetujuan" yang dibuat di dalam masyarakat untuk menghindari adanya konflik sosial (Gaffikin, 2008:168). Setiap orang dalam masyarakat setuju untuk tidak melakukan tindakan yang akan merugikan pihak lain. kontrak sosial ini pada umumnya dikuatkan oleh peraturan pemerintah atau, dalam hal profesi, dikuatkan oleh standar profesi. Kode etik bagi profesional, adalah kontrak atau persetujuan untuk tidak melakukan tindakan-tindakan yang melanggar yang akibatnya akan merugikan pihak lain.

Gaffikin (2008:178) membuat daftar tentang karakteristik profesional dan mendapatkan ada 6 (enam) hal yang umumnya sering disebut, yaitu, "Possession of a skill based on theoretical knowledge, provision of training and an education, testing of competence of members, organization, adherence to a code of conduct, and altruistic service". Yang menarik untuk disimak adalah "altruistic service". Apakah altruistic? Menurut Merriam Webster Online Dictionary, altruistic berarti "unselfish regard for or devotion to the welfare to others", yaitu suatu prinsip hidup yang lebih mendahulukan kesejahteraan dan kebahagiaan orang lain daripada diri sendiri. Sikap semacam ini adalah sikap yang tidak mementingkan diri sendiri. Sementara bila dihubungkan dengan etika, altruistic adalah suatu teori sikap yang menganggap kebaikan kepada orang lain sebagai tujuan dari tindakan moral. Perilaku altruistic tampak ketika individu berinteraksi dengan individu lain, yaitu menolong orang lain tanpa pamrih, perhatian terhadap penderitaan orang lain tanpa pamrih, dan mendahulukan kepentingan orang lain daripada dirinya sendiri tanpa pamrih. Tantangannya adalah: dapatkah profesi akuntan memiliki sikap ini?

\section{Akuntan Publik}

Akuntan publik (akuntan independen/akuntan ekstern) adalah akuntan yang memberikan jasa-jasanya atas dasar pembayaran tertentu. Jasa yang dapat diberikan oleh seorang akuntan publik umumnya adalah melakukan pemeriksaan (audit) atas laporan keuangan, untuk memberikan opini audit. Menurut Chicakli (2002), akuntan publik adalah akuntan yang bersertifikasi dan memperoleh gelar profesi CPA (Certified Public Accountant). Kelebihan akuntan publik (CPA) dibanding akuntan lainnya adalah: 
"1) higher level of knowledge and experience with serving clients. 2) Greater experience with issues involving independence and objectivity. 3) Deeper understanding of matters which are not traditionally in the domain of accounting, such as personal financial planning and information technology consulting, but which are related to accounting and serving client. 4) Credentials. And 5) More experience working with other professionals such as attorneys, brokers, agents, etc."

Kelebihan akuntan publik tersebut tampaknya tidak relevan dengan skandal keuangan yang terjadi di dunia. Sikap sosio-sprititual (perilaku altruistic) perlu diterapkan pada akuntan publik, terutama auditor yang memberikan opini akuntan. Hal ini penting karena output atau hasil laporan auditor mempengaruhi keputusan yang diambil oleh pemakai laporan keuangan auditan.

Burchel et al. (1985) menjelaskan bahwa tantangan yang dihadapi profesi akuntan adalah, "As a result of its failure to react to new environmental circumstances the accounting profession is facing something of a crisis; a crisis in part of public confidence and in part of identity (Gilling. 1976, pp. 64)".

Sampai saat inipun, krisis kepercayaan dan krisis identitas adalah tantangan bagi akuntan publik. Bagaiana cara mengatasi krisis ini? Salah satu caranya adalah perlunya perubahan perilaku akuntan yang lebih bersikap sosio-spiritual (sikap altruistic). Perubahan sikap juga ditekankan oleh Wyatt (2004) menyatakan perlunya melakukan "reestablishing professionalism", salah satunya dengan cara:

"The leaders of the firms need to understand that the firm's internal culture requires substantial amount of attention if the reputation of the firms is to be restored. No peace of legislation is likely to solve the behavior changes that have evolved within the firms over the past 30 years."

\section{Akuntan Manajemen}

Yang dimaksud akuntan manajemen disini adalah akuntan internal perusahaan. Tugas utama akuntan manajemen adalah mendukung kebutuhan informasi bagi manajemen. Seiiring dengan berubahnya lingkungan, maka kebutuhan perusahaan akan informasi juga berubah. Perubahan terjadi karena beberapa faktor, diantaranya: perubahan dalam ekonomi dunia dan struktur sosial, globalisasi pasar, perkembangan teknologi, pentingnya kualitas, dan good corporate governance. Tantangan bagi akuntan manajemen tidak hanya kemampuannya untuk mampu menyediakan informasi yang sesuai dengan perkembangan akan tetapi juga harus benar-benar melaksanakan konsep good corporate governance dan bukan sekedar propaganda (misalnya, kasus elpiji oleh Pertamina).

Terkait dengan informasi untuk pasar modal, Jensen (2008) membuktikan bahwa ada manipulasi earnings yang dilakukan perusahaan dan adanya kolusi antara analis dan perusahaan. Untuk itu, Jensen menyarakan agar menanamkan integritas dalam perekayasaan laporan keuangan. Integritas yang dimaksud adalah, "The quality or state of being complete, unbroken conditions, wholeness, and entirety; the quality 
or state of being unimpered, perfect condition, and soundness; and the quality or state of being sound moral principles, uprightness, honesty, and sincerity."

\section{Akuntan Sektor Publik}

Semula akuntan sektor publik dikenal sebagai akuntan pemerintah. Dengan perkembangan akuntansi sektor publik, peran akuntan juga berkembang menjadi akuntan sektor publik. Organisasi sector public mengalami banyak tantangan dengan adanya isu-isu reformasi. Di negara-negara berkembang, fokusnya adalah membangun dan memperkuat dasar infrastruktur pendidikan dan kesehatan, yang merupakan sarana untuk menanggulangi kemiskinan. Kesulitan utama yang dihadapi akuntan sektor publik adalah bagaimana mengukur kinerja sector public termasuk kinerja pemerintah. Freer (2002) berpendapat bahwa akuntan sektor publik berada di dalam pusat reformasi akuntansi sektor publik, yang meliputi, "Control, probity, accountability, improving value for money, measuring and rewarding success, managing risk, enabling change, improving performance, supporting good decision making, and good government governance”.

Di Indonesia, tidak hanya infrastruktur pendidikan dan kesehatan yang harus dibangun, akan tetapi kinerja pemerintah juga harus diperbaiki. Banyaknya kasus korupsi yang melibatkan berbagai departemen dalam pemerintah, berdampak berkurangnya kepercayaan masyarakat pada pemerintah. Suparto (2005) mengungkapkan adanya "penyakit egois" dalam diri para pejabat pemerintahan. Hal ini terungkap dari permintaan Presiden SBY, yang dikutip sebagai berikut:

"Presiden meminta para pejabat pemerintah agar lebih sering turun ke lapangan untuk melihat kehidupan nyata masyarakat di pelosok negeri yang menjadi kantong kemiskinan. Para pejabat diimbau untuk tidak terlena di ruang berpendingin atau ruang rapat mewah. Hakikatnya para pejabat diharapkan lebih mau memerhatikan orang lain ketimbang dirinya sendiri."

Permintaan Presiden SBY tersebut mencerminkan bahwa sikap sosio-spiritual (sikap altruistic) perlu diamalkan dalam lingkungan akuntansi sektor publik.

\section{Akuntan Syariah}

Profesi akuntan syariah muncul setelah makin berkembangnya akuntansi syariah. Sejarah akuntansi syariah sebenarnya sudah lama lahir, jika diruntut, muncul sejak ada perintah membayar zakat. Adanya perintah membayar zakat mendorong pemerintah untuk membuat laporan keuangan secara periodik Baitul Maal. Sedangkan para pedagang atau produsen muslim wajib menghitung hartanya apakah sudah sesuai dengan nishabnya (Utomo, 2008:14). Akuntansi syariah menjadi berkembang setelah didirikannya Bank Muamalat pada tahun 1991. Dan pada tahun 2010, mulai diadakan serifikasi bagi profesi akuntan syariah.

Oleh karena profesi ini masih baru, banyak tantangan yang dihadapi para akuntan syariah, diantaranya, yang paling krusial, adalah pembuatan beberapa standar tentang praktik-praktik syariah yang masih perlu ditinjau ulang sehubungan dengan 
sikap sosio-spiritual. Spiritualitas terbukti meningkatkan kejujuran dan kepercayaan dalam organisasi (Wagner-Marsh dan Conely, 1999). Saputro dan Triyowono (2009) dalam penelitiannya tentang konsep nilai tambah syariah menegaskan tiga hal. Pertama, definisi nilai tambah yang ada berpotensi membawa kembali paham kapitalisme ke dalam akuntansi syariah melalui utilitarianisme etika. Kedua, definisi dan konsep nilai tambah cenderung untuk mendistribusikan kesejahteraan hanya untuk kalangan terbatas stakeholder. Dan ketiga, dalam beberapa kasus, format laporan nilai tambah tidak menunjukkan simplicity principle yang ada dalam Islam.

Hasil riset ini membuktikan kembali bagaimana faham kapitalis dan individualism masih mempengaruhi praktik-praktik akuntansi syariah. Oleh karena itu, penting bagi para akuntan syariah untuk mengembalikan praktik akuntansi syariah sesuai dengan ajaran Islam, yang menjadi tuntunan umat Islam untuk menjadi lebih bijak dan bajik (learned and virtuousness).

\section{Akuntan Pendidik}

Menurut pendapat saya, profesi akuntan pendidik adalah profesi yang paling penting dibandingkan profesi akuntan lainnya, karena dari tangan akuntan pendidiklah lahir akuntan-akuntan lainnya. Oleh karena itu, pendidikan akuntansi merupakan tantangan yang paling berat yang harus dihadapi akuntan. Pendidikan dan penelitian di bidang akuntansi harus lebih menenkankan pada dimensi moral dan etika sehingga perlu dukungan dari pendidik dan terdidik untuk melakukan perubahan dalam proses pendidikan. Blair et al. (2007), menekankan pentingnya perubahan kurikulum dan metode pengajaran:

"....there are currently serious omissions from the accounting curriculum that need to be rectified .... Accounting students are miseducated in certain critical areas ... there is tendency to inculcate student with a convenient mythology rather than to educate ... It is critical for accounting educators to de-mythologize the curriculum".

(Ravenscroft and William 2004:8)

Akuntansi perlu dilihat dan dipotret lebih luas dan tidak hanya dianggap sebagai catatan atau praktik-praktik teknis. Sudah tidak tepat lagi untuk mengajarkan hanya bagaimana cara mencatat transaksi dan melaporkannya. Memang keahlian teknis akuntansi diperlukan bagi profesi akuntan, akan tetapi akuntansi bukan sekedar informasi untuk pengambilan keputusan dan pertanggung jawaban. Akuntansi juga merupakan konstruksi sosial yang menghasilkan ilmu pengetahuan ekonomi dan sosial. Akuntansi juga merupakan kekuatan sosial (social power) yang mampu merubah tindakan individu, perusahaan, proses, dan mentranformasikannya untuk mencapai tujuan tertentu. Penerapan akuntansi yang buruk atau salah atau bahkan sempit, berpengaruh terhadap lingkungan sosial. Sebut saja dalam sejarah, akuntansi mendorong terjadinya kapitalisme dan pendistribusian sumber daya hanya untuk kepentingan tertentu. Penerapan akuntansi yang demikian harus diubah dan tampaknya "tugas mulia" ini menjadi tanggung jawab akuntan pendidik. 
Bila demikian, bagaimankah seharusnya pendidikan akuntansi dilaksanakan? Proses belajar mengajar seharusnya tidak hanya mempelajari fakta-fakta praktik akuntansi, akan tetapi juga membuat model pembelajaran yang lebih utuh (more holistic learning model). Pendidikan akuntansi harus berisi tentang perspektif sosial dan spiritual akuntansi dengan mengaktifkan berbagai elemen pedagogy. Blair et al. (2007) meyimpulkan bahwa "Accounting educational change must encompass the content and practice of classroom activity, but it also requires change to the selfconciuousness of all actors involved. Explicit inclusion of the social, critical, environmental and ethical dimensions of accounting..."

Hal yang sama mulai diantisipasi oleh Badan Standar Nasional Pendidikan (BSNP). Dalam draft paradigm pendidikan nasional abad 21, ditekankan bahwa perguruan tinggi sebagai pengawal nilai.

"Sebagai pengawal nilai, maka perlu kiranya setiap institusi serta civitas academica menyadari betapa besar pengaruh teknosains pada kehidupan social, ekonomi, budaya, dan politik...., dan seluruh insan akademis ikut bertanggung jawab untuk mengarahkan ciptaan dan karyanya yang tepat guna, tepat sasaran, estetis dan etis. Sikap terbuka, toleran, menghormati prestasi, menghargai kejujuran/integritas, penuh motivasi diri, dan bertanggung jawab adalah kepribadian yang dituntut dalam paradigm teknosains".

BSNP juga menekankan fungsi pendidikan yaitu: mengembangkan ketrampilan dan ilmu pengetahuan (transfer and production of skill and knowledge); penyalur dan pengembang watak (karakter) luhur; dan pembangunan tumbuhnya rasa kebangsaan.

Dari uraian tentang profesi akuntan kontemporer, tantangan utamanya adalah melaksanakan etika professional yang didasarkan pada sikap sosio-spiritual. Sikap sosio-spiritual adalah sikap akuntan yang dilandasi tidak hanya oleh aturan-aturan pemerintah dan standard setter, akan tetapi lebih menekankan pada sikap yang dilandasi oleh sifat sosial dan spiritual yang secara lahiriah ada dalam diri manusia. Sifat sosial mencerminkan kepedulian akuntan terhadap sesama, teman profesi, keluarga, dan lingkungannya. Sedangkan sikap spiritual mencerminkan "kebajikan" manusia yang bisa juga disebut sebagai perilaku altruistic.

\section{Akuntansi Kontemporer - Suatu Imajinasi Diri}

Tak dapat dipungkiri bahwa perkembangan ilmu baik itu ilmu pengetahuan, llmu alam atau ilmu yang dipelajari dari berbagai disiplin lainnya termasuk artifak karena mereka merupakan hasil imajinasi manusia (Sunder, 2007). Sebelum ditemukan pesawat terbang, orang berimajinasi seandainya dia bisa terbang. Ada pepatah Indonesia yang mengatakan "bagai pungguk merindukan bulan" dan kemudian ilmu pengetahuan mengantarkan manusia untuk mendarat di bulan. Banyak lagi imajinasi manusia lainnya yang pada akhirnya menjadi bahan pemikiran manusia untuk dikembangkan.

Akuntansi sebagai salah satu artifak (hasil pemikiran manusia) juga berkembang dari imajinasi kita. Dengan demikian, saya kemudian berandai-andai dan 
menjadi bertanya-tanya, "akuntansi seperti apa yang akan terjadi di masa depan? Berikut hasil imajinasi diri atas akuntansi kontemporer di masa yang akan datang.

\section{Akuntansi sebagai suatu komoditas bebas}

Terinspirasi dari apa yang dilakukan oleh manajemen program doktor ilmu akuntansi (PDIA) Universitas Brawijaya terhadap kurikulum program studi akuntansi, manajemen telah membuat kurikulum yang "beyond positivism". Kurikulum baru ini memperkenalkan paradigma-paradigma baru atau disebut sebagai "multi paradigm". Selain itu pihak menajemen program studi akuntansi juga mematenkan kurikulumnya yang "unik" itu. Sehingga apabila ada universitas atau program studi lain yang tertarik dengan kurikulum yang "unik" tersebut, mereka harus membeli patennya. Apa yang dilakukan oleh manajemen PDIA adalah membuat kurikulum sebagai barang komoditas berupa paten. Saya kemudian berimajinasi, mengapa akuntansi tidak melakukan hal yang sama?

Praktik-praktik akuntansi selalu mendapat sorotan tajam mengingat perannya yang penting sebagai penyedia informasi untuk pengambilan keputusan ekonomi. Peraturan-peraturan dari pemerintah dan standard setter dilakukan untuk membuat informasi yang disajikan menjadi lebih berkualitas. Akuntansi kemudian menjadi monopoli pembuat peraturan. Bila ada ide-ide atau pendapat-pendapat baru tentang praktik akuntasi, tidak akan diindahkan sepanjang tidak disetujui oleh pembuat peraturan. Bila akuntansi dibiarkan berkembang sehingga praktik-praktik baru akan muncul. The best practice kemudian dipatenkan dan mereka yang ingin menggunakan praktik tersebut harus membelinya. Apakah hal ini akan memperburuk situasi yang ada sekarang dimana pemerintah dan standard setter gagal melindungi ekonomi dan pembuat keputusan? Atau apakah hal ini akan mengembalikan akutansi ke era kekuasaan manajemen? Mungkin tidak, bila dalam membuat the best practice. Akuntan dilandasi oleh code of honor, integritas, moral, dan etika.

\section{Akuntansi yang memiliki jiwa}

Dipandang dari paradigma spiritualisme, dalam ajaran agama (Islam), dikenal dua malaikat (Malaikat Munkar dan Nakir) yang diberi tugas untuk mencatat positif dan negatif yang dilakukan manusia. Jika kita (akuntan) mencatat dengan cermat kekayaan dan kewajiban kita dari sisi material, mengapa kita tidak melakukan hal yang sama dari sisi spiritual? Mengapa kita harus menunggu hasil catatan kedua malaikat tersebut?

Saya berimajinasi bila kita (para akuntan), dalam satu tahun berupaya meluangkan waktu sejenak atau berlibur untuk merenungkan apa yang telah kita lakukan (melakukan introspeksi diri melalui penjelajahan jiwa). Dalam kegiatan perenungan tersebut, kita ambil kertas dan bagi kertas tersebut menjadi dua kolom. Kolom kiri diberi judul positif (debet) dan kolom kanan dengan judul negatif (kredit). Selanjutnya, kita merinci kegiatan positif dan negatif apa saja yang telah kita lakukan. Termasuk dalam kegiatan positif adalah bagaimana dan seberapa sering kita melakukan hubungan dengan pencipta kita, melaksanakan ajaran-ajaran agama, serta 
menjauhi larangan yang ada dalam agama kita. Bagaimana hasilnya? Sudah seimbangkah neraca kita? Bila lebih banyak kegiatan positif, berari ada saldo positif (mewakili laba). Atau sebaliknya, bila lebih banyak kegiatan negative, berarti ada saldo negative (terjadi rugi). Apabila tahun tersebut terjadi rugi, pertanyaannya adalah: bagaimana agar kita menjadi akuntan yang lebih baik?; apa yang membuat kita melakukan hal-hal negatif? Setelah itu lakukan analisis trend dengan membandingkan catatan kita tahun-tahun sebelumnya. Pelajari rasio positif dan negative yang telah kita lakukan. Bagaimana hasilnya?

Memang, batasan positif dan negatif adalah batasan yang subyektif yang tergantung pada masing-masing individu atau sifatnya "relative". Akan tetapi paling tidak ada norma-norma dan nilai-nilai spiritual yang kita anut, yang member kita pemahaman tentang tindakan-tindakan positif dan negative. Jadi, dengan melakukan instropeksi diri secara spiritual, para akuntan akan memiliki komitmen untuk memperbaiki diri dan lingkungannya, yang pada gilirannya akan mempengaruhi praktik-praktik akuntansi.

\section{Akuntansi yang altruistic}

Di dalam salah satu program acara televisi di salah satu stasiun TV, dalam salah satu episodenya menampilkan cerita tentang pahlawan-pahlawan altruis. Sebut saja nama-nama seperti Fathul Khoiri (penolong korban bom Ritz Carlton JW Marriott Juli 2009), Achmad Usman (penolong korban bom Kedubes Australia September 2004), Agus Bambang Priyanto (penolong korban bom Bali I, Oktober 2002) dan Endang Aripin (mengorbankan diri untuk menolong orang tenggelam di Jepang dan dihormati sebagai pahlawan masyarakat Jepang). Kisah mereka sangat mengharukan dan membangkitkan decak kagum yang luar biasa (Radityo, 2009). Mereka adalah contoh orang-orang yang tidak egois. Orang-orang yang mendahulukan kesejahteraan dan kebahagiaan orang lain dari pada diri sendiri.

Terinspirasi dari cerita atau berita tentang pahlawan-pahlawan altruistic tersebut, saya mencoba berimajinasi tentang akuntansi yang altruistic. Bayangkan bila kita memiliki akuntansi yang altruistic! Skandal-skandal yang mencoret nama baik akuntan mungkin tidak akan terjadi. Bayangkan bila akuntansi tidak hanya sebagai penyedia informasi untuk membuat keputusan, akan tetapi akuntansi juga mencoba menolong orang lain untuk tidak mementingkan diri sendiri. Akuntansi mempunyai kekuatan untuk merubah sikap egoisme seseorang menjasi sikap yang altruis. Bayangkan bila di dunia ini hanya ada akuntan-akuntan altuistik, maka tidak perlu lagi adanya peraturan pemerintah dan standard setter. Akuntan akan selalu berusaha memberikan informasi yang jujur, yang dilandasi sikap percaya, empati, dan tidak bermaksud membuat informasi untuk keuntungan pihak tertentu.

Bagaimana caranya? Marilah kita pertimbangkan praktik berpuasa dalam bulan suci Ramadan bagi umat Muslim. Berikut adalah tulisan Djazuri (2010) tentang puasa:

Puasa (shaum atau shiam) artinya -dalam bahasa Arab-menahan (al-imsak). "Menahan" ini bertingkat-tingkat. Dimulai dari menahan diri dari makan minum dan 
nafsu seksual; menahan segala panca indera dari berbuat dosa; sampai dengan menahan hati dan pikiran dari bersambung (connect) dengan selain Allah. Jadi yang dituju dari ibadah, termasuk puasa dalam hal ini, bukanlah bentuk formalnya, tetapi pesan spiritualnya. Salah satu pesan puasa adalah puasa sebagai instrumen untuk melatih keikhlasan, kesabaran dan memagari diri dari segala kemenyimpangan dari jalan Allah. Puasa dalam pesan spiritual ini melatih seorang muslim untuk tetap teguh di jalan Allah apapun godaan yang merayunya untuk menyimpang dari jalan Allah. Muara dari berpuasa adalah menanamkan takwa dalam diri setiap pelaku puasa agar menjadi kekuatan penggerak (driving force) dalam segala aktifitasnya dalam hidup ini. Ibarat puasa sebagai madrasah, sekolah atau universitas, diharapkan setelah tamat, umat Islam tetap mengamalkan apa yang diajarkan selama masa pendidikan. Jika kelas doktoral misalnya membiasakan pesertanya untuk meneliti, menulis, berpikir analitis dan seterusnya, maka setelah tamat pun, kebiasaan tersebut tetap harus dipertahankan. Jika tidak, maka pendidikannya dalam perspektif yang lebih luas, dapat dikatakan tidak berhasil.

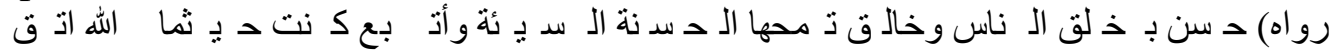

$$
\begin{aligned}
& \text { الـ الـ ترمذي }
\end{aligned}
$$

Artinya: Bertakwalah kepada Allah dimanapun kamu berada, iringi perbuatan buruk dengan perbuatan baik, karena perbuatan baik akan menghapusnya dan bergaullah dengan orang lain dengan perilaku yang baik. (Hadits diriwayatkan oleh at-Tirmidzi dengan status hasan atau hasan shahih).

Bayangakan bila akuntan pendidik mampu menanamkan sikap altruistic dalam mata kuliah akuntansi, dan setelah lulus, akutan tersebut akan mengamalkan apa yang diajarkan selama masa kuliah.

Akuntansi adalah produk dari kehidupan yang ada di dunia ini, dan seperti syair pada lagu yang dipopulerkan oleh Achmad Albar - dunia ini....panggung sandiwara - maka terserah pada kita (para akuntan) untuk mengambil peran apa di panggung tersebut. Dalam memainkan peran tersebut perlu dipertimbangkan tidak hanya sikap individualism tetapi juga sikap social-spiritual.

Akuntansi adalah artifak (hasil pemikiran manusia). Sama seperti hasil pemikiran manusia lainnya, karya manusia berasal dari imajinasi manusia itu sendiri. Dengan pemikiran tersebut, saya kemudian berimajinasi tentang "akuntansi di masa depan". Dalam imajinasi saya, akan muncul akuntansi sebagai suatu komoditas bebas, akuntansi yang memiliki jiwa, dan akuntansi yang altruistik. Imajinasi akuntansi sebagai suatu komoditas bebas merupakan bagian dari peran akuntansi dalam ekonomi, sedangkan tiga imajinasi yang terakhir, mengimajinasikan akuntansi dari sikap sosio-spiritual. Mungkikah hal ini terjadi? Mengutip kata bijak George Bernard Shaw yang ada pada awal tulisan ini, "why not?"

Akuntansi bukan sekedar angka-angka atau hitungan, karena akuntansi merupakan hasil dari interaksi sosial yang terjadi dalam kehidupan bermasyarakat. Akuntansi sosial sudah lahir sejak dulu, dengan membawa faham kapitalisme dan individualism. Namun demikian, akuntansi sosial berkembang secara kontemporer terjadi karena kekhawatiran terhadap etika perusahaan, kekuasaan perusahaan, dan 
menurunnya ekologi lingkungan. Kekhawatiran terhadap menurunnya ekologi lingkungan, mendorong munculnya akuntansi lingkungan dan sustainability accounting. Menurunnya ekologi lingkungan sebenarnya merupakan hasil kerja manusia yang terlalu serakah dan selalu mencoba mencari keuntungan untuk diri sendiri tanpa memedulikan sosial dan lingkungan sekitarnya. Sedangkan menurunnya etika perusahaan dicerminkan dari berbagai skandal perusahaan yang mencoreng nama baik akuntan. Hal ini mendorong munculnya akuntansi spiritual yang berusaha melakukan keseimbangan semua aspek yang ada dalam kehidupan, yaitu fisik, mental, ekologi, dan spiritual.

\section{SIMPULAN}

Sikap sosio-spiritual perlu diimplemantasikan dalam akuntansi. hal ini merupakan tantangan bagi profesi akuntan, bukan saja bagi akuntan publik, tetapi juga bagi profesi akuntan lain seperti: akuntan manajemen, akuntan sektor publik, akuntan syariah, dan akuntan pendidik.

Bagi akuntan publik, tantangannya adalah dengan mengembalikan kepercayaan masyarakat yang berkurang karena adanya skandal-skandal keuangan. Riset membuktikan bahwa skandal tersebut dapat terjadi karena kurangnya peraturan pemerintah dan standard setter. Akan tetapi, riset secara kualitatif menyarankan bahwa skandal keuangan terjadi karena sifat manusia pada dasarnya adalah egois, artinya hanya mementingkan diri sendiri tanpa memedulikan orang lain. Dengan demikian, perlu ditambahkan sikap altruistic di dalam dalam kode etik akuntan publik.

Tantangan yang dihadapi akuntan manajemen adalah bagaimana akuntan manajemen mampu membatu manajer untuk memberikan informasi yang jujur. Dalam membuat laporan keuangan perlu ditanamkan sikap integritas yang meliputi sound moral principle, uprightness, honesty, sincerety, dan melaksanakan code of honor.

Akuntan sektor publik menghadapi tantangan akuntabilitas dan menurunnya kepercayaan masyarakat terhadap lembaga pemerintahan. Dalam lembaga pemerintahan perlu juga ditanamkan sikap altruistic.

Akuntan syariah menghadapi tantangan standard setter yang berusaha membawa akuntansi syariah kearah kapitalisme.

Akuntan pendidik mendapat tantangan terberat untuk menanamkan pemahaman bahwa akuntansi bukan sekedar praktik-praktik teknis, akan tetapi akuntansi juga memilki nilai sosial-spriritual. Sikap sosio-sprititual dalam akuntansi dapat diajarkan kepada para calon akuntan melalui pendidikan manusia seutuhnya dengan cara membuat model pembelajaran yang utuh (holistic learning model). Sehingga pada saat mereka lulus, maka mereka akan mengamalkan tidak hanya teknik-teknik untuk praktik akuntansi, tetapi juga sikap sosio-spiritual yang melandasi praktik akuntansi tersebut. 


\section{DAFTAR PUSTAKA}

Badan Standar Nasional Pendidikan (BSNP). 2010. "Draft Paradigma Pendidikan Nasional Abad XXI". Bahan Sosialisasi dan Diskusi di FK Universitas Brawijaya. 28 September: pp.1-92.

Barrachina, Mercedes, Vicente Ripoll, and Susana Gago. 2004. "Social research evolution in management accounting". Reflection using Bunge's theory, Critical Perspective Accounting 15. pp. 701-713.

Blair, Bill, Gordon Boyce, Cindy Davids, and Susan Greer. 2007. "Reflecting on contemporary accounting: teaching and learning social and critical perspectives. Proceeding of the second innovation in accounting and corporate governance education conference". 31 January-2 February. Hobart, Tasmania.

Brown, Lawrence D., John C. Gardner, and Miklos A. Vasarhelyi. 1990. "Attributes of articles impacting contemporary accounting literature". Contemporary Accounting Research. Vol. 5. No. 2, pp. 793-815.

Burchel, Stuart, Collin Club, and Anthony G. Hopwood. 1985. "Accounting In Its Social Context: Towards A History of Value Added In The United Kingdom”. Accounting, Organizations, and Society. Vol. 10. No. 4; pp. 381413.

Burchel, Stuart, Collin Club, Anthony G. Hopwood, and Janine Nahapiet. 1980. "The roles of accounting in organizations and society". Accounting, Organizations, and Society, Vol. 5, No. 1; pp. 5-27.

Chichakli, Richard A. 2002. "What is a CPA". http://www.txcpa.net/the_cpa.htm.

Chua, Wai Fong. 1996. "Teaching and learning only the language of number monolingualism in a multilingual world". Critical Perspective on Accounting Vol. 7, No.2; pp. 129-155.

Djazuri, Muhammad Akram. 2010. "Tujuan Puasa untuk perbaikan ruhani". http://lomba.kompasiana.com/group/puasa-dulu-baru lebaran/2010/08/08/tujuan-puasa-untuk-perbaikan-ruhani.

Evans, Lee. 2010. "Observation on the changing language of accounting", http://www.edwards.usask.ca/special/5ahic/papers/5AHIC62\%20Final\%20pa per.pdf.

Evans, Thomas, G. 2003. "Accounting Theory: Contemporary Accounting Issues", Thompson Learning, USA

Freer, Steve. 2002. "Keeping pace with the changing rule of the public sector accountant. www.cipfa.org.uk/international/.../pres_sf_2002.doc

Gaffikin, Michael. 2008. "Accounting theory: Research, regulation, and accounting practice". Pearson Education, Australia.

Gray, Rob. 2002. "The social accounting project and accounting organizations and society: Privileging engagement, imaginings, new accountings and pragmatism over critique?" Accounting, Organization, and Society, 27, pp. 687-708. 
Hendriksen, E.S. and M.F. Van Breda. 1992. Accounting Theory, Irwin, Homewood, Illinois, USA.

Jensen, Michael C. 2008. "Putting integrity into finance theory and practice: A positive approach", Negotiation, Oranization and Markets Research Paper: Harvard NOM Research Paper No. 06-06 and Barbados Group Working Paper No. 01-06.

Kariyawasam, Udayasri. 2009. "Changing Role of the Management Accountant. Keynote address at the Achievers CIMA Graduation ceremony on 30 August 2009 at

BMICH". http://www.sec.gov.lk/pdf/Changing_Role_of_Management_Accountant__CIMA\%20v2.pdf

Sukoharsono, Eko Ganis. 2008. "Religion, spirituality, and philosophy: how do they work for an accounting world? The third Postgraduate Consortium in Accounting: Socio Spiritual Accounting". The Department of Accounting. The University of Brawijaya.

Sunder, Shyam. 2007. "Imagined Worlds of Accounting". http://ssrn.com/sbstract=964702. diakses tanggal 16 Oktober 2010.

Saputro, Andik S. Dwi dan Iwan Triyuwono. 2009. "Koreksi konsep nilai tambah Syariah: Menimbang pemikiran konsep dasar teoritis laporan keuangan akuntansi Syariah", Proceeding Simposium Nasional Akuntansi XII, Samarinda, pp. 1-25.

Suparto, Toto. 2005. "Krisis pemimpin altruis". Media Indonesia, Selasa, 14 Juni.

Syafiq Mahmadah Hanafi dan Achmad Sobirin. 2002. Relevansi Ajaran Agama Dalam Aktifitas Ekonomi (Studi Komparatif Antara Ajaran Islam dan Kapitalisme). Prosiding Simposium Nasional I Sistem Ekonomi Islam.

Triyuwono, Iwan. 2006. Perspektif, Metodologi, Dan Teori Akuntansi Syariah. Edisi

Satu. Jakarta : PT RajaGrafindo Persada.

Turner, Lynn E. 2006. "Learning from accounting history: Will we get it right this time?", Issues in Accounting Education, Vol. 21, No. 4, November, pp. 383407.

Utomo, Budi Setiawan. 2008. “Akuntansi Zakat: Sebuah keharusan”, Laporan utama, Majalah Akuntan Indonesia: Mitra dalam Perubahan Edisi No. 2, Tahun I, Oktober, pp.14-19.

Venkatesh, G. 2010. "Three bottom line approach to individual and global sustainability", Problems of Sustainable Development Vol. 5, No.2, pp. 29-37.

Wagner-Marsh, F. and Conely J. 1999. "The fourth wave: The spirituality based firm". Journal of Organizational Change Management Vol. 12 No. 4, pp. 292301.

Wolcott, Susan K. 2010. Sustainability Accounting: What is it and How to teach it. Paper presented at CPE Workshop, AAA Meeting, August 1, San Fransisco. http://commons.aaahq.org/files/a46e7ff3f7/CPE_Handout_100730.pdf.

Wyatt, Arthur R. 2004. "Commentary: Accounting profesionalism - they just don't get it!". Accounting Horizons Vol. 18, No.1, March, pp. 45-53. 